\title{
Spasmolytic effect of Lonicera japonica extracts on isolated uterus smooth muscle contractions
}

\author{
Hassan Sadraei $^{\left.1^{\star(}\right)}$, Mona Khakboo $^{1^{\circledR}}$, Gholamreza Asghari ${ }^{(\mathbb{}}$ \\ ${ }^{1}$ Department of Pharmacology and Toxicology, School of Pharmacy and Pharmaceutical Sciences, Isfahan University of Medical Sciences, Isfahan, I.R. \\ Iran \\ ${ }^{2}$ Department of Pharmacognosy, School of Pharmacy and Pharmaceutical Sciences, Isfahan University of Medical Sciences, Isfahan, I.R. Iran
}

\section{A R T I C L E I N F O}

\section{Article Type:}

Original Article

\section{Article History:}

Received: 13 March 2021

Accepted: 23 May 2021

\section{Keywords:}

Lonicera japonica

Extract

Essential oil

Uterus

Spasm

\begin{abstract}
A B S T R A C T
Introduction: Honeysuckle (Lonicera japonica) is an ornamental flowering plant with numerous traditional medicinal uses. It has been claimed to have anti-spasmodic activities, but only limited studies have been done to support this. The objective of this research was to investigate anti-spasmodic effect of $L$. japonica flower extract on uterus contractions.

Methods: Hydroalcoholic extract was prepared using the maceration technique. In addition, chloroform and ethyl acetate fractions were prepared using a solvent in solvent fractionation technique. Essential oils were collected using the hydro-distillation technique.

Rat isolated uterus was suspended in an organ bath and contracted with oxytocin, acetylcholine (ACh), KCl, or application of electrical field stimulation (EFS). The relaxant effects of the extract, its fractions, and nifedipine were examined on uterine contrition induced by the above-mentioned stimuli.

Results: Nifedipine in a concentration-dependent manner inhibited uterine contraction induced by oxytocin, $\mathrm{KCl}, \mathrm{ACh}$, and EFS. L. japonica flower extract also exhibited an inhibitory effect on the isolated rat uterus. Comparison of the hydroalcoholic extract with its chloroform and ethyl acetate fractions showed that the chloroform fraction was the most potent and the ethyl acetate the weakest part of the plant with antispasmodic activity. The relaxant effect of essential oil had close similarities to that of chloroform extract.

Conclusion: Lipophilic compounds isolated by the chloroform partition of crude hydroalcoholic extract of L. japonica flower exhibited the most antispasmodic activity. Ethyl acetate partition of the same extract exhibited the least activity. Therefore, it can be concluded that the spasmolytic constituents of L. japonica flower reside in chloroform partitioning. The nonpolar essential oils may also have a contribution.
\end{abstract}

Implication for health policy/practice/research/medical education:

This paper provides pharmacological evidence for spasmolytic actions of Lonicera japonica extracts on isolated uterus. Potent antispasmodic constituents lie within the chloroform fraction. Separation of active components may result in the identification of a suitable lead compound for preterm labor control.

Please cite this paper as: Sadraei H, Khakboo M, Asghari G. Spasmolytic effect of Lonicera japonica extracts on isolated uterus smooth muscle contractions. J Herbmed Pharmacol. 2021;10(3):351-358. doi: 10.34172/jhp.2021.41.

\section{Introduction}

Honeysuckles are herbaceous shrubs plants belonging to the Lonicera genus in the Caprifoliaceae family (1). Although honeysuckle is native to Korea, Japan and China, however, it is cultivated as a colorful, fragrant garden flower all over the world, including Iran $(2,3)$. Among 180 identified species of honeysuckle, L. caucasica, $L$. floribunda, L. iberica, L. nummulariifolia, and L. japonica are mostly found in Iran $(3,4)$. Although honeysuckle has been introduced as an ornamental plant nevertheless, it is widely known as herbal medicine, especially in China
(5). For instance, L. Japonica flowers have been used in feverish conditions for clearing heat from the body (6). The stem and branches are used to remove heat from the acupuncture meridians by stimulating the circulation of energy (6). They are also used to treat feverish colds and dysentery and as a cooling remedy in combination with other herbs for the acute stages of rheumatoid arthritis (6). L. periclymenum flowers are traditionally made into syrup, taken as an expectorant for bad coughs and asthma and as a diuretic (6). Other traditional applications of honeysuckle include antiviral and antibacterial activities, particularly 
in cold and influenza (2). In Chinese traditional medicine, honeysuckle is one of the most important Chinese herbs for clearing heat and poisons from the body (2).

Phytochemical analysis reported the existence of tannins, flavonoids, mucilage, salicylic acid, and sugars in various species (2). Among 140 separated chemical constituents, most components belong to essential oil, organic acids, and polyphenols (2). Several active components have been isolated from this plant, including apigenin, luteolin, quercetin, chrysoeriol, hyperoside, lonicerin, rhoifolin, rutin, and chrysin which are thought to be responsible for pharmacological activities. Linalool, farnesole, cholorogenic acid, isochlorogenic acid, caffeic acid, hexadecanoic acid, and myristic acid are the most abundant organic acids found in the essential oil (2). Other identified constituents include glycosides such as centauroside, swerosid, loganin and saponins such as macranthoside, loniceroside, and dipsacoside (2).

Preclinical biological studies of $L$. japonica extracts have confirmed several pharmacological activities with therapeutical potentials, including antimicrobial activities (5). Aqueous and ethanolic extracts of the plant have been reported to have anti-inflammatory action in various animal models $(7,8)$. Some of the plant constituents have antioxidant activities (9). An aqueous extract containing chlorogenic acid has shown to have protective effect against hepatic toxicity of alcohol in an animal model (10). Other reported pharmacological activities include immunomodulatory properties $(11,12)$, anti-tumor action (13), anti-hyperglycemic, anti-hyperlipidemic $(14,15)$, anti-aggregatory (16), and neuroprotective properties, which may have therapeutic values in Alzheimer and Parkinson's diseases $(17,18)$.

Honeysuckle has traditionally been used for asthma, urinary complaints, and in childbirth. It is believed that it has antispasmodic activities on smooth muscles, which improve gastrointestinal spasmodic pain and inflammation $(2,6)$. Modern experimental investigations confirm antispasmodic activity of $L$. japonica extract on rabbit ileum contractions $(19,20)$. Although many research works have been reported about $L$. japonica species, however, less attention has been paid to its antispasmodic potential. So far there is no report about the effect of $L$. japonica on uterus smooth muscle, while it has been said that L. japonica has an effect on childbirth (6). Therefore, the objective of this research was to evaluate the pharmacological actions of $L$. japonica extract on isolated uterus contractions.

\section{Methods and Materials}

\section{Drugs and solutions}

Hydroalcoholic, chloroform, ethyl acetate extracts, and essential oil were prepared from honeysuckle flowers as described below. For pharmacological studies, hydroalcoholic, chloroform, ethyl acetate extracts, and essential oil were prepared as $80 \mathrm{mg} / \mathrm{mL}$ stock solution in dimethyl-sulfoxide (DMSO). Nifedipine was made up in DMSO as $1 \mathrm{mg} / \mathrm{mL}$ stock solution. Further dilution was made in distilled water. $\mathrm{KCl}$ was made up in distilled water as $2 \mathrm{M}$ stock solution. Acetylcholine ( $\mathrm{ACh}$ ) was made up in distilled water as $100 \mathrm{mM}$ stock solution; further serial dilution was made as appropriate. Oxytocin ampule (Caspian, Iran) was diluted by distilled water as $0.1 \mathrm{IU} / \mathrm{mL}$ stock solution. Further dilutions were made in distilled water. Tyrode's physiological solution was prepared in distilled water as follow: $\mathrm{NaCl}(137 \mathrm{mM}), \mathrm{KCl}(2.7 \mathrm{mM})$, $\mathrm{CaCl}_{2}$ (1.8mM), NaHCO 3 (11.9mM), $\mathrm{MgCl}_{2}$ (1.05mM), $\mathrm{NaH}_{2} \mathrm{PO}_{4}(0.42 \mathrm{mM})$, and glucose $(5.6 \mathrm{mM})$. Nifedipine and ACh were from Sigma, and other compounds were from Merck (China). Estradiol valerate ampoule was from Aburaihan Pharmaceutical Company (Iran).

\section{Extracts preparation}

Honeysuckle flowers were collected from a garden in the Isfahan University campus in the Spring of 2020 and identified as L. japonica by the Botanist Dr Ali Bagheri at Biology Department of Isfahan University (Iran). Flowers were dried in shadow with access to fresh air. Dried flowers were pulverized into a fine powder using an electrical mill (Keep, Korea). The hydroalcoholic extract was obtained using the maceration procedure (21). In this method, the powder was moist with $70 \%$ ethanol for two hours before it was soaked into ethanol ( 1 to 8 ratio) for 3 days. The extract was separated and the process repeated again until eluent color faded away. The collected extract was evaporated using a rotary apparatus (Heidolph, Germany) at $40^{\circ} \mathrm{C}$ with 90 revolution per minute and the yield of dry extract was calculated.

Further extraction was performed on $50 \mathrm{~g}$ hydroalcoholic extract using an equal volume of chloroform and water mixture in $1 \mathrm{~L}$ decanter. After 20 minutes vigorous shaking, the solvents were allowed to settle down, and the lower chloroform phase was decanted. Another $500 \mathrm{~mL}$ chloroform was added to the vessels and the procedure repeated two more times. The collected chloroform fraction was left under the hood for evaporation of chloroform. The remaining aqueous solution was then mixed with an equal volume of ethyl acetate. Agitation continued as before and the lower ethyl acetate partition was eluted. This process was repeated three times by adding further $500 \mathrm{~mL}$ fresh ethyl acetate into the aqueous solution. The collected ethyl acetate fraction was concentrated at $30^{\circ} \mathrm{C}$ in the rotary. For the preparation of essential oil, $250 \mathrm{~g}$ grind honeysuckle flowers were immersed in $2.5 \mathrm{~L}$ distilled water in Soxhlet extractor and heated to reflux (22).

Pharmacological procedures

Antispasmodic actions of honeysuckle extracts were examined on non-pregnant rat isolated uterus. Wistar 
female rats (180-220 g), purchased from the School of Pharmacy and Pharmaceutical Sciences animal house, were treated with a single intraperitoneal (IP) injection of estradiol $(100 \mu \mathrm{g} / \mathrm{kg})$. This rat remained in a separate cage in the animal house with full access to food and water. The next day the rat was killed by carbon dioxide asphyxiation, and the abdominal cavity was wide opened. Uterine horns were identified, carefully dissected out, and placed in oxygenated Tyrode's solution at room temperature. The tissue was trimmed off the adhering adipose tissues and cut into two sections. Both tip edges of the tissue were ligated with two separate cotton threads. One end of the tissue was secured into a hook and placed in an organ bath filled with Tyrode's solution at $37 \mathrm{C}$ and continuously gassed with oxygen. The other thread tail was attached to Harvard isotonic transducer lever under $1 \mathrm{~g}$ tension. The transducer was attached to the Harvard Universal Oscillograph pen recorder apparatus for recording tissue contractions.

Initially the tissue was washed with Tyrode's solution and allowed to relax for at least 20 minutes. Tissues suspended in the organ bath were contracted by either addition of spasmogens or neuronal electrical stimulation. Spasmogens were directly added into the organ bath to give rise to a final bath concentration of $0.001 \mathrm{IU} / \mathrm{mL}$ for oxytocin, $1 \mu \mathrm{M}$ for $\mathrm{ACh}$, and $80 \mathrm{mM}$ for $\mathrm{KCl}$. For neuronal stimulation of tissue, electrical field stimulation (EFS) manner was adapted. A designed stimulator applied direct square pulses via a pair of platinum wires placed alongside of the tissue using $6 \mathrm{~V}$ output, $50 \mathrm{~Hz}$ frequency and 1 second stimulation duration. EFS was applied at 10 minutes intervals until reproducible responses were recorded. The first concentration of the extract was added and EFS response was evaluated 10 minutes later. This procedure was repeated with two folds increment in the extract concentration for the construction of the concentration-response curve using the non-cumulative approach. The effects of the extract on oxytocin and ACh responses were also examined in a non-cumulative manner. Oxytocin and ACh were 5 minutes and 30 seconds in contract with the tissue, respectively. Tissue washing was performed with emptying the bath and refilling with fresh Tyrode's solution. In the case of $\mathrm{KCl}$, a cumulative approach was used. In this case, after the establishment of $\mathrm{KCl}$ contraction, the successive concentrations of the extract were added into the organ bath without washing at 10 minutes intervals. The effects of the standard drug (nifedipine) and the extract vehicle (DMSO) were examined in a similar manner.

\section{Data analysis}

Effect of honeysuckle extracts were examined on six different tissues after establishing effective concentration ranges. The recorded uterus contraction was analyzed by measuring contraction amplitude from the settled baseline and expressed as a percentage of contraction recorded prior to addition of the extracts. Data were presented as mean \pm standard error of mean (SEM) and plotted as semilogarithmic concentration-response curve. When appropriate, inhibitory concentration causing $50 \%$ of the maximum response $\left(\mathrm{IC}_{50}\right)$ was calculated. For statistical analysis, one-way analysis of variance (ANOVA) was used for intragroup comparison, and Student's $t$ test was used for comparing intergroup differences. $P$ value less than 0.05 was considered statistically significant. SigmaPlot computer program (version 11) was used for statistical analysis and plotting the graphs.

\section{Results}

The yield of hydroalcoholic extract was calculated as $40 \%$ of the dried flower $(\mathrm{W} / \mathrm{W})$. The yield of chloroform and ethyl acetate fractions were $2 \%$ and $3.4 \%$, respectively. The yield of the essential oil was $0.09 \%$.

Rat uterus primed with estradiol produced irregular spontaneous rhythmic contractions when suspended in the organ bath under $1 \mathrm{~g}$ tension. The addition of oxytocin $(0.001 \mathrm{IU} / \mathrm{mL})$ augmented uterus rhythmic contractions. Following washing the tissue, the uterine contraction was diminished to the original baseline. Nifedipine in a concentration-dependent manner inhibited oxytocin induced response (Figure 1). The addition of $\mathrm{KCl}(80 \mathrm{mM})$ into the bath, on the other hand, produced a sustained contraction of the uterus, which was maintained during the course of the experiment. Nifedipine concentrationdependently reduced $\mathrm{KCl}$ tonic response (Figure 1). The

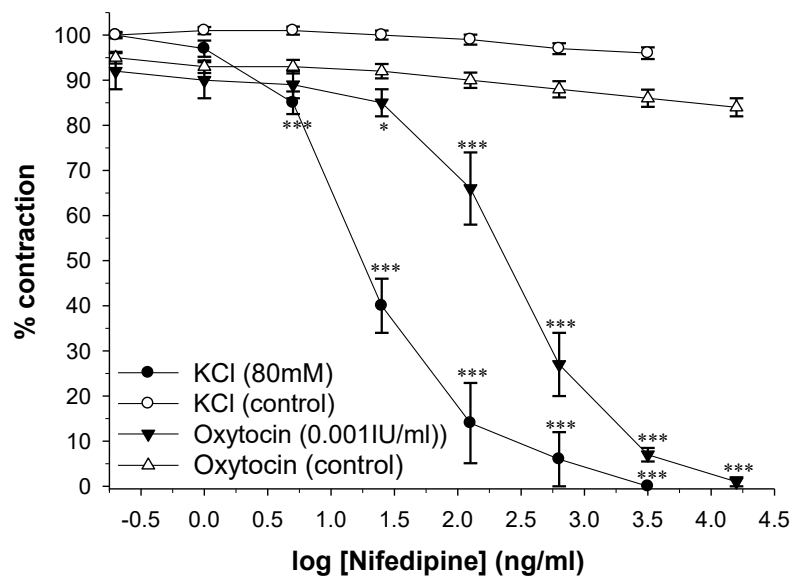

Figure 1. The relaxant effect of nifedipine on contractions induced by $\mathrm{KCl}$ and oxytocin on isolated rat uterus. The experiment was conducted with parallel time-matched control tissue receiving an equal volume of vehicle (DMSO). Uterus contractions are expressed as a percentage of initial tissue response prior to the addition of nifedipine. The results are presented as mean \pm SEM for each group of data $(n=6)$ and compared for statistical difference with their corresponding point in the time-matched vehicle-treated group (Student's t-test, ${ }^{*} P<0.05$, ${ }^{* * *} P<0.001$ ). There was no statistically significant change in the vehicle-treated control groups over the course of studies (ANOVA). 
addition of $\mathrm{ACh}(1 \mu \mathrm{M})$ into the tissue bath caused a sharp spike contraction within the contract time and then returned to the baseline after the washing. This phasic ACh response was suppressed by nifedipine (Figure 2). The application of single pulse of EFS induced a rapid contraction which returned to the base baseline without washing the tissue. Similar to ACh, the EFS contractile response of the isolated rat uterus was diminished in the presence of nifedipine (Figure 2).

The addition of hydroalcoholic extract of $L$. japonica neither induced spasmogenic activity on rat isolated tissue suspended in the tissue bath nor potentiated uterine contractile responses to oxytocin, $\mathrm{ACh}, \mathrm{KCl}$, or EFS. On the contrary, L. japonica hydroalcoholic extract had an explicit inhibitory effect on isolated uterus contractions. The relaxant effect on oxytocin response was observed with $200 \mu \mathrm{g} / \mathrm{mL}$ concentration and reduced to about 50\% with $3.2 \mathrm{mg} / \mathrm{mL}$ extract in the bath (Figure 3). Chloroform fraction separated from the hydroalcoholic extract of $L$. japonica had profound inhibitory effect on uterus smooth muscle. The inhibitory effect was started with $50 \mu \mathrm{g} / \mathrm{mL}$ chloroform extract in the bath and complete inhibition was achieved with $1.6 \mathrm{mg} / \mathrm{mL}$ bath concentration (Figure 3). Ethyl acetate fraction, differentiated from remaining aqueous extract, only exhibited a tiny inhibitory response at its highest used concentration compared to the DMSO treated control groups (Figure 3). Further increase in concentration was unattainable because DMSO inhibitory action became prominent.

Chloroform fraction of $L$. japonica extract, in a concentration-dependent manner, inhibited phasic contractile responses to ACh $(1 \mu \mathrm{M})$. Significant reduction

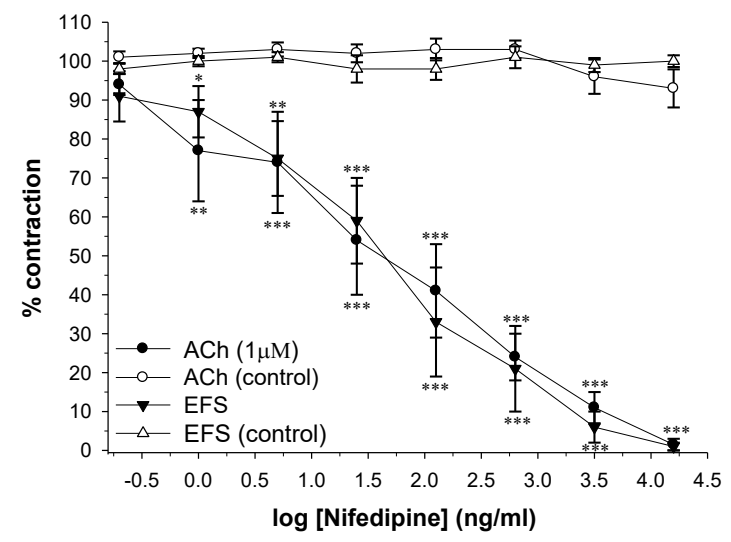

Figure 2. The relaxant effect of nifedipine on contractions induced by acetylcholine (ACh) and electrical field stimulation (EFS) on isolated rat uterus. The experiment was conducted with parallel time-matched control tissue receiving equal volume of vehicle (DMSO). Uterus contractions are expressed as a percentage of initial tissue response prior to the addition of nifedipine. The results are presented as mean \pm SEM for each group of data $(n=6)$ and compared for statistical difference with their corresponding point in the time-matched vehicle-treated group (Student's t-test, $\left.{ }^{*} P<0.05,{ }^{* * *} P<0.001\right)$. There was no statistically significant change in the vehicle-treated control groups over the course of studies (ANOVA). in ACh response was seen with $200 \mu \mathrm{M}$ bath concentration, and with $1.6 \mathrm{mg} / \mathrm{mL}$ bath concentration, the total relaxation was accomplished (Figure 4). Hydroalcoholic extract of $L$. japonica had less potent inhibitory effect on rat uterus and with bath concentration of $3.2 \mathrm{mg} / \mathrm{mL}$ still, $36 \%$ of the initial response to ACh remained (Figure 4). There were no significant differences between ethyl

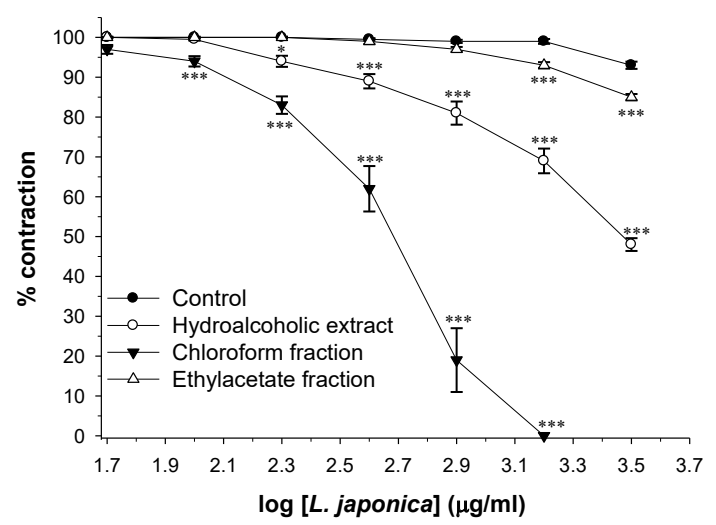

Figure 3. The relaxant effect of hydroalcoholic extract and its chloroform and ethyl acetate fractions of $L$. japonica on contractions induced by oxytocin on isolated rat uterus. Experiments were conducted with parallel time-matched control tissue receiving equal volume of vehicle (DMSO). Uterus contractions are expressed as a percentage of initial uterine response prior to the addition of the extracts. The results are presented as mean \pm SEM for each group of data $(n=6)$ and compared for statistical difference with their corresponding point in the time-matched vehicletreated group (Student's t-test, ${ }^{*} P<0.05,{ }^{* * *} P<0.001$ ). There was no statistically significant change in the vehicle-treated control groups over the course of studies (ANOVA).

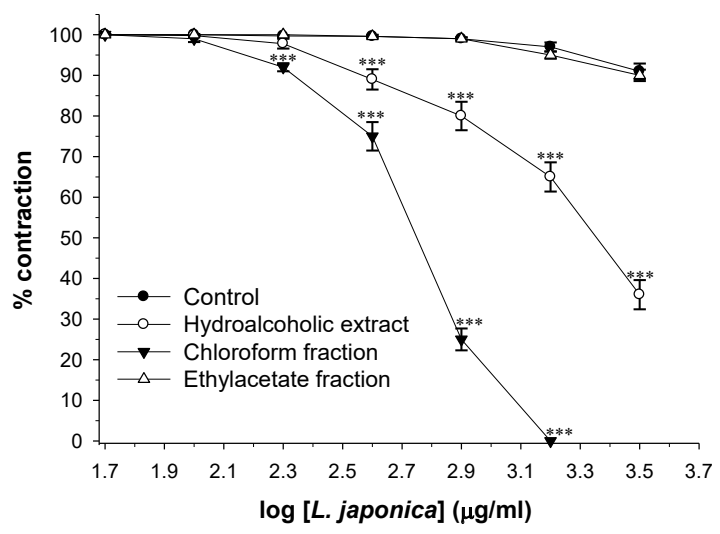

Figure 4. The relaxant effect of hydroalcoholic extract and its chloroform and ethyl acetate fractions of $L$. japonica on contractions induced by acetylcholine (ACh) on isolated rat uterus. Experiments were conducted with parallel time-matched control tissue receiving an equal volume of vehicle (DMSO). Uterus contractions expressed as a percentage of initial uterine response prior to the addition of the extracts. The results are presented as mean \pm SEM for each group of data $(n=6)$ and compared for statistical difference with their corresponding point in the time-matched vehicle-treated group (Student's t-test, ${ }^{\star} P<0.05$, ${ }^{* * \star} P<0.001$ ). There was no statistically significant change in the vehicle-treated control groups over the course of studies (ANOVA). 
acetate extract and DMSO treated control group on ACh induce contraction (Figure 4). Further increase in the extract concentration proved to be infeasible because DMSO action became dominant.

Chloroform fraction of $L$. japonica extract had a profound inhibitory action on uterus smooth muscle response to EFS. Significant attenuation of EFS response was obtained with $50 \mu \mathrm{g} / \mathrm{mL}$ chloroform extract in the bath and total relaxation was seen with $800 \mu \mathrm{g} / \mathrm{mL}$ bath concentration (Figure 5). Hydroalcoholic extract of $L$. japonica also inhibited EFS response but with higher bath concentration. With the highest used concentration $(3.2$ $\mathrm{mg} / \mathrm{mL}$ ), EFS response was reduced by just $66 \%$ (Figure 5 ), although part of hydroalcoholic extract action could be due to inhibitory effect of DMSO (see Figure 5). There was no significant effect between ethyl acetate and DMSO treated group response to EFS (Figure 5).

Hydroalcoholic extract of L. japonica concentrationdependently inhibited tonic contractile response induced by $\mathrm{KCl}(80 \mathrm{mM})$. Chloroform fraction of the extract had a similar action, however, at a much lower concentration (Figure 6). With a bath concentration of $1.6 \mathrm{mg} / \mathrm{mL}$, the chloroform extract abolished the $\mathrm{KCl}$ tonic response while hydroalcoholic extract attenuated the response just by $37 \%$ at a similar concentration (Figure 6). There was no significant difference between the ethyl acetate fraction and DMSO treated tissues (Figure 6).

Essential oil of L. japonica concentration-dependently attenuated both tonic and phasic contractions of rat uterus

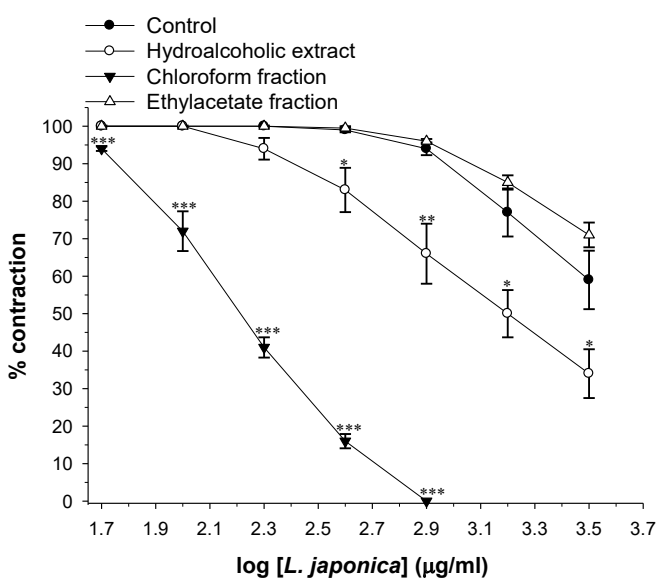

Figure 5. The relaxant effect of hydroalcoholic extract and its chloroform and ethyl acetate fractions of $L$. japonica on contractions induced by electrical filed stimulation (EFS) on isolated rat uterus. Experiments were conducted with parallel time-matched control tissue receiving an equal volume of vehicle (DMSO). Uterus contractions are expressed as a percentage of initial uterine response prior to the addition of the extracts. The results are presented as mean \pm SEM for each group of data $(n=6)$ and compared for statistical difference with their corresponding point in the time-matched vehicle-treated group (Student's t-test, ${ }^{*} P<0.05$, $\left.{ }^{* *} P<0.01,{ }^{* *} P<0.001\right)$. The differences in the mean value among the vehicle-treated control group was greater than those would be by chance over the course of studies (ANOVA, $P<0.001$ ). induced by $\mathrm{KCl}$ and $\mathrm{ACh}$, respectively (Figure 7). Total abolishment of the contractions was achieved with bath concentrations of $1.6 \mathrm{mg} / \mathrm{mL}$ and $3.2 \mathrm{mg} / \mathrm{mL}$ for $\mathrm{KCl}$ and ACh, respectively. The inhibitory concentration causing $50 \%$ of maximum response $\left(\mathrm{IC}_{50}\right.$ ) of the essential oil is compared with various extract fractions in Table 1.

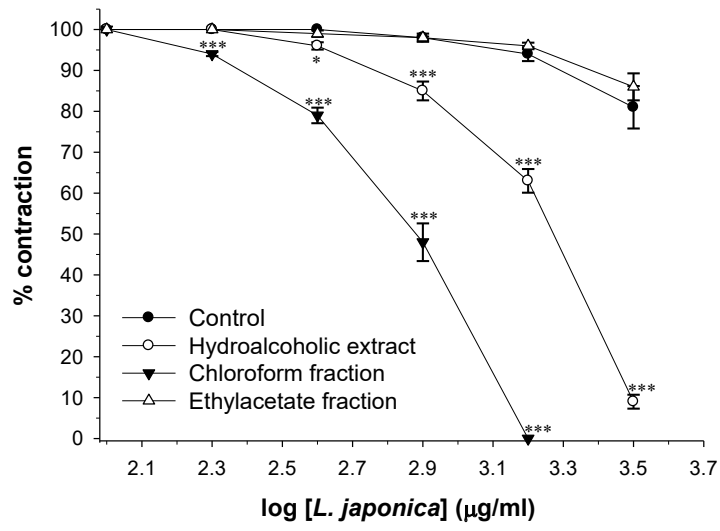

Figure 6. The relaxant effect of hydroalcoholic extract and its chloroform and ethyl acetate fractions of $L$. japonica on contractions induced by $\mathrm{KCl}(80 \mathrm{mM})$ on isolated rat uterus. Experiments were conducted with parallel time-matched control tissue receiving an equal volume of vehicle (DMSO). Uterus contractions are expressed as the percentage of initial uterine response prior to the addition of the extracts. The results are presented as mean \pm SEM for each group of data $(n=6)$ and compared for statistical difference with their corresponding point in the time-matched vehicle-treated group (Student's t-test, ${ }^{*} P<0.05$, ${ }^{* * *} P<0.001$ ). The differences in the mean value among the vehicle-treated control group was greater than those would be by chance over the course of studies (ANOVA, $P<0.001$ ).

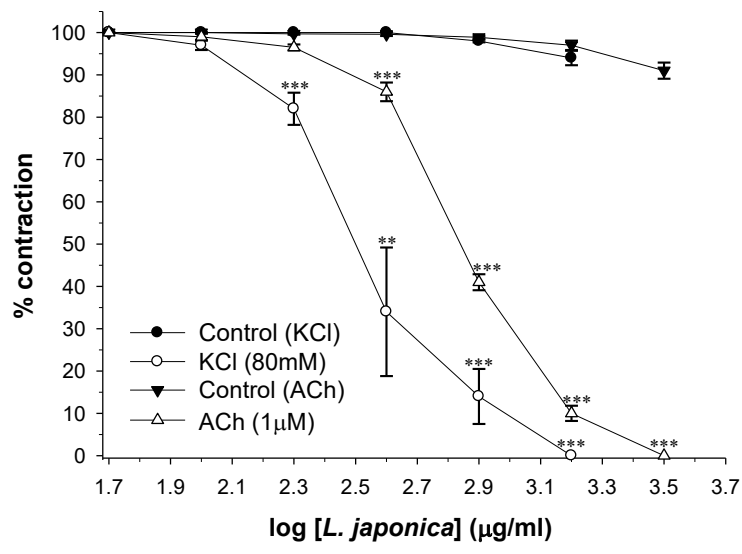

Figure 7. The relaxant effect of essential oil of $L$. japonica on contractions induced by $\mathrm{KCl}$ and acetylcholine (ACh) on isolated rat uterus. Experiments were conducted with parallel time-matched control tissue receiving an equal volume of vehicle (DMSO). Uterus contractions are expressed as a percentage of initial uterine response prior to the addition of the extracts. The results are presented as mean \pm SEM for each group of data $(n=6)$ and compared for statistical difference with their corresponding point in the time-matched vehicle-treated group (Student's t-test, $\left.{ }^{* *} P<0.01,{ }^{* * *} P<0.001\right)$. There was no statistically significant change in the vehicle-treated control groups over the course of studies (ANOVA). 
Table 1. Inhibitory concentration of $L$. Japonica fractions causing $50 \%$ of maximum response $\left(\mathrm{IC}_{50}\right)$ in rat isolated uterus

\begin{tabular}{|c|c|c|c|c|}
\hline Treatment & $\mathrm{KCl}$ & Oxytocin & $\mathrm{ACh}$ & EFS \\
\hline Nifedipine & $22 \pm 3.3 \mathrm{ng} / \mathrm{mL}$ & $325 \pm 97.7 \mathrm{ng} / \mathrm{mL}$ & $130 \pm 54 \mathrm{ng} / \mathrm{mL}$ & $205 \pm 143 \mathrm{ng} / \mathrm{mL}$ \\
\hline Hydroalcoholic extract & $1.8 \pm 0 \mathrm{mg} / \mathrm{mL}$ & $3.1 \pm 0.15 \mathrm{mg} / \mathrm{mL}$ & $2.2 \pm 0.2 \mathrm{mg} / \mathrm{mL}$ & $1.85 \pm 0.4 \mathrm{mg} / \mathrm{mL}$ \\
\hline Chloroform extract & $766 \pm 59 \mu \mathrm{g} / \mathrm{mL}$ & $500 \pm 76 \mu \mathrm{g} / \mathrm{mL}$ & $551 \pm 26 \mu \mathrm{g} / \mathrm{mL}$ & $163 \pm 13 \mu \mathrm{g} / \mathrm{mL}$ \\
\hline Essential oil & $391 \pm 63 \mu \mathrm{g} / \mathrm{mL}$ & - & $704 \pm 23 \mu \mathrm{g} / \mathrm{mL}$ & - \\
\hline
\end{tabular}

The results are presented as mean \pm SEM for each group of data $(n=6)$. $\mathrm{KCl}(80 \mathrm{mM})$, oxytocin $(0.001 \mathrm{IU} / \mathrm{mL}), \mathrm{ACh}(\mathrm{acetylcholine}, 1 \mu \mathrm{M})$, EFS (electrical filed stimulation, $50 \mathrm{~Hz}, 1 \mathrm{~S}$ duration, $6 \mathrm{~V}$ output).

\section{Discussion}

For many years herbal plants have played a crucial role in the treatment of ailments (23). However, they rarely have been given specific indications and are generally suggested to be useful for several unrelated diseases (23). This could be because herbal plants contain vast diversity of phytochemical compounds with different biological activities. Usually a combination of chromatographic and purification methods are used for isolation, purification, and identification of plant constituents (21). Although phytochemical screening assay is an important tool for identifying general structure, it gives no indication about the intrinsic bioactivity of the isolated compounds. A more rapid and feasible screening approach is the implication of the bioactivity-guided fractionation technique (21). In this way, proper actions can be taken to assure that potential active constituents are not missed.

Extraction and fractionation are regarded as the crucial first step in the analysis of medicinal plants (21). Maceration is a conventional method, involved soaking plant material in a hydroalcoholic solvent for a period of time (21). The hydroalcoholic extract of $L$. japonica prepared in this way, inhibited rat isolated uterus contraction induced by $\mathrm{KCl}, \mathrm{ACh}$, EFS, and oxytocin, confirming the existence of active constituents with antispasmodic properties. Bioactive compounds in the hydroalcoholic extract of L. japonica consist of multicomponent mixtures (2). Nevertheless, the nature of the bioactive components is unknown. Therefore, the extract prepared by conventional method was fractionated by the relative solubility in two different immiscible liquids in order to further concentrate biologically active compound. Thus, for the defined bioactivity testing, the extract was solubilized in chloroform and water mixtures. In this way, compounds are separated base on their polarity differences. In this procedure, the lipophilic compounds were mainly partitioned into the chloroform phase while hydrophilic compound remained in the aqueous solution. Chloroform fraction of $L$. japonica in a concentration-dependent manner inhibited rat isolated uterus contractions induced by $\mathrm{KCl}, \mathrm{ACh}, \mathrm{EFS}$, and oxytocin but at much lower concentrations. Examination of antispasmodic activity of the chloroform fraction proved that most of the spasmolytic bioactive components are dissolved in the chloroform phase. For instance, the chloroform fraction was $2.3,4,11$ and 6.2 times more potent than the original hydroalcoholic extract in inhibiting $\mathrm{KCl}, \mathrm{ACh}, \mathrm{EFS}$, and oxytocin responses, respectively (Table 1). Essential oils are non-polar lipophilic substances that could be responsible for the observed relaxant effect. Therefore, the inhibitory effect of the essential oil prepared by the Soxhlet method from plant powder materials was also examined on uterus contractions. The method of Soxhlet extraction is a conventional technique, which gives a high essential oil yield from plant materials (22). The essential oil of $L$. japonica in a concentration-dependent manner inhibited uterus contractions induced by $\mathrm{KCl}$ and $\mathrm{ACh}$.

In comparison with the chloroform fraction, the essential oil was two times more potent in respect to inhibition of $\mathrm{KCl}$ response (Table 1). However, the essential oil was less potent than the chloroform fraction for inhibiting ACh contractile response in isolated rat uterus (Table 1). Although the essential oils are non-polar substances, they only could have a minor contribution to the inhibitory effect of the chloroform fraction. Because, first of all, the essential oils were very volatile and could have been evaporated during rotary process. Secondly, essential oils only accounts for very small percentage of plant constituents. Therefore, it is likely that in addition to the essential oil, other components with potent antispasmodic potential existed in the chloroform fractions, which would have been participated in the inhibitory effect of the chloroform fraction. Thus, it is recommended that chloroform fraction constituents be separated by column chromatography and screen for their antispasmodic activities.

Further liquid-liquid extractions were continued with ethyl acetate. The extraction was performed against water. Ethyl acetate has a medium polarity, which enables it to extract semi-polar compounds. Thus, it can extract a significant portion of the polyphenols from the aqueous solution. This partitioning solution removes less polar compounds including non-glycosylated flavonoid (24). Ethyl acetate fractionation is a common method used for separation of polyphenols based compounds (24).

Anti-spasmodic activity of ethyl acetate fraction was then determined on rat isolated uterus contractions. However, it turns out that the polyphenol rich-fraction had weak anti-spasmodic activity. Flavonoids are polyphenols compounds, some of which are known to 
have substantial spasmolytic activity (25). Flavonoids mainly exist in glycoside form in the plant, which lacks antispasmodic activity in vitro (25). Therefore, it might be that the amount of aglycone form of flavonoid was not enough since the glycoside form remains in the aqueous solution.

Consumption of traditional medicinal plant, which is believed to have antispasmoic activity, may affect normal uterine contractions. However, in the process of drug design and development, the effects of drugs on uterus contractile activity are not routinely investigated. In this research, rat uterus contraction was induced in four different ways in order to make wider comparison of the relaxant activity. Uterus smooth muscle is more sensitive to spasmogens during pregnancy and the estrus phase when the uterus is primed with estrogens $(26,27)$. Pretreatment with estradiol synchronizes the rat uterus as they are in the estrus phase and potentiates spontaneous activity, as seen in all the experiments. Oxytocin is a nonapeptide that selectively contracts the uterine smooth muscle. The high sensitivity of the tissue to oxytocin is seen in the appropriate hormonal environment. Estrogen induces oxytocin receptor synthesis and consequently increases the sensitivity to oxytocin. The physiological function of oxytocin is to augment uterus rhythmic contractions by direct stimulation of phasic uterine contractions. By acting through oxytocin receptors, oxytocin causes the release of $\mathrm{Ca}^{2+}$ from intracellular stores and indirectly activates voltage activated $\mathrm{Ca}^{2+}$ channels (28). An increase in cytosols $\mathrm{Ca}^{2+}$ ions triggers uterus smooth muscle contractions (28). ACh is a natural neurotransmitter directly acting on the smooth muscle muscarinic receptors and induces contraction by releasing $\mathrm{Ca}^{2+}$ ion from the intracellular stores (29). EFS depolarizes neurons embedded in the uterus wall and causes the release of neurotransmitters, including ACh (27,30). Extracellular high concentration of $\mathrm{KCl}$ directly depolarizes the uterus smooth muscle and thereby actives voltage activated $\mathrm{Ca}^{2+}$ channels (31). Similarities between the relaxant effect of nifedipine and L. japonica extract indicate that the relaxant effect of active constituents of the extract is somehow affecting cytosol $\mathrm{Ca}^{2+}$ ions enhancement during tissue stimulation. The amount of constituents with antispasmodic activity in the ethyl acetate fraction is so small to produce substantial relaxation of the uterine activity.

\section{Conclusion}

Although plant materials are regarded as an important source for drug screening, blind separation and identification of a phytochemical substance are proved to be expensive and time-consuming. In this study, a bioactivity-based approach was applied to validate antispasmodic activity of L. japonica extract. Chloroform and ethyl acetate fractions were prepared using classical liquid-liquid extraction. Comparison of spasmolytic activity revealed that most active constituents have nonpolar properties.

\section{Acknowledgement}

This project was part of Pharm D. thesis of Mona Khakboo as Pharm D. student at the Isfahan University of Medical Sciences.

\section{Authors' contributions}

HS was project manager and supervised the pharmacological studies. GA supervised extract preparation. MK was responsible for the experimental work and analysis of data. HS was responsible for writing the paper. All authors approved the final manuscript for publication.

\section{Conflict of interests}

The authors declare no conflict of interests.

\section{Ethical considerations}

Animal care and experiments were performed in accordance with the guidelines for the care and use of laboratory animals of the Isfahan University of Medical Sciences. The project was confirmed by the ethical committee of the university (IR.MUI.RESEARCH. REC.1399.096).

\section{Funding/Support}

This research project was financially supported by the Research Department of Isfahan University of Medical Sciences (Project No: 399049).

\section{References}

1. Williams PA, Timmins SM. Biology and ecology of Japanese honeysuckle (Lonicera japonica) and its impacts in New Zealand. Wellington, New Zealand: Department of Conservation; 1999.

2. Shang $\mathrm{X}$, Pan $\mathrm{H}$, Li $\mathrm{M}$, Miao $\mathrm{X}$, Ding $\mathrm{H}$. Lonicera japonica Thunb.: ethnopharmacology, phytochemistry and pharmacology of an important traditional Chinese medicine. J Ethnopharmacol. 2011;138(1):1-21. doi: 10.1016/j.jep.2011.08.016.

3. Zhengyi W, Peter HR. Flora of China. Vol 19. Beijing: Missouri Botanical Garden Press; 2011. p. 621-37.

4. Ghahreman A. Flora of Iran. Vol 20. Tehran: Tehran University Publications; 2000. p. 2443. [Persian].

5. Li Y, Cai W, Weng X, Li Q, Wang Y, Chen Y, et al. Lonicerae japonicae flos and Lonicerae flos: a systematic pharmacology review. Evid Based Complement Alternat Med. 2015;2015:905063. doi: 10.1155/2015/905063.

6. Ody P. Complete Guide to Medicinal Herbs. Herbal remedies for common ailments. 2nd ed. London: Dorling Kindersley; 2000:85.

7. Cui XY, Wang SX, Hou YL. Anti-inflammatory mechanism of the Lonicera japonica Thunb extract. China Pharmacy. 2007;18(24):1861-3.

8. Zhou XG, Liang SL, Hu CH. Inhibitory effect on acute 
inflammation of ethanol extract from Lonicera japonica. Pratical Clinical Medicine. 2012;13(2):12-21.

9. Chaowuttikul C, Palanuvej C, Ruangrungsi N. Pharmacognostic specification, chlorogenic acid content, and in vitro antioxidant activities of Lonicera japonica flowering bud. Pharmacognosy Res. 2017;9(2):128-32. doi: 10.4103/pr.pr_117_16.

10. Zhou C, Su Y, Li F. Protective effect of honeysuckle extracts on chemically-induced injury in mice liver. Mod Food Sci Technol. 2010;26(4):351-3.

11. Zhu X. Pharmacological effects and clinical situation analysis of Lonicera japonica flos. Med Health Care. 2014;22(5):64-5.

12. Zhou X, Li Z, Liu Z. Effect of Lonicera japonica Flos extract made by different methods on immunologic function of rats. Pract Prev Med. 2011;18(11):2052-4.

13. Park HS, Park KI, Lee DH, Kang SR, Nagappan A, Kim JA, et al. Polyphenolic extract isolated from Korean Lonicera japonica Thunb. induce G2/M cell cycle arrest and apoptosis in HepG2 cells: involvements of PI3K/Akt and MAPKs. Food Chem Toxicol. 2012;50(7):2407-16. doi: 10.1016/j.fct.2012.04.034.

14. Pan JQ, Liu HC, Liu GN. Honeysuckle can reduce the level of blood glucose and blood lipid of mice. Guangzhou Pharm. 1998;29(3):59-61.

15. Wang Q, Chen DH, Deng WL. Effect of extracts from Lonicera flos on blood lipid and blood glucose. Pharmacol Clin Chin Materia Med. 2007;23(3):40-2.

16. Chang WC, Hsu FL. Inhibition of platelet activation and endothelial cell injury by polyphenolic compounds isolated from Lonicera japonica Thunb. Prostaglandins Leukot Essent Fatty Acids. 1992;45(4):307-12. doi: 10.1016/09523278(92)90088-z.

17. Wang P, Liao W, Fang J, Liu Q, Yao J, Hu M, et al. A glucan isolated from flowers of Lonicera japonica Thunb. inhibits aggregation and neurotoxicity of A $\beta 42$. Carbohydr Polym. 2014;110:142-7. doi: 10.1016/j.carbpol.2014.03.060.

18. Kwon SH, Hong SI, Jung YH, Kim MJ, Kim SY, Kim HC, et al. Lonicera japonica THUNB. protects 6-hydroxydopamineinduced neurotoxicity by inhibiting activation of MAPKs, PI3K/Akt, and NF- $\kappa$ B in SH-SY5Y cells. Food Chem Toxicol. 2012;50(3-4):797-807. doi: 10.1016/j.fct.2011.12.026.

19. Song SJ, Li FF, Xu Y, Zhang LH, Yuan F, Zhang Y. [Effects of honeysuckle flower and Scutellaria baicalensis Georgi on constraction and electric activity of rabbit small intestine smooth muscle]. Zhongguo Ying Yong Sheng Li Xue Za Zhi. 2009;25(3):344-8.

20. Minggen W, Shaojiang N, Shengbao L, Ruhai Y, Qing W, Kangjian N. Effect of honeysuckle preparation decocted with water and deposited with alcohol on in vitro small intestine movement of domestic rabbit. Chinese Agricultural Science Bulletin. 2005;21(6):32-4.

21. Sasidharan S, Chen Y, Saravanan D, Sundram KM, Yoga Latha L. Extraction, isolation and characterization of bioactive compounds from plants' extracts. Afr J Tradit Complement Altern Med. 2011;8(1):1-10.

22. Okonkwo CO, Ohaeri OC. Comparative study of steam distillation and soxhlet for the extraction of botanical oils. Asian J Biol Sci. 2020;13:62-9. doi: 10.3923/ajbs.2020.62.69.

23. Samuelsson G, Bohlin L. Drugs of Natural Origin: A Treatise of Pharmacognosy. 6th ed. Stockholm: Swedish Pharmaceutical Press; 2009. p. 70-2.

24. Kim DO, Lee KW, Lee HJ, Lee CY. Vitamin C equivalent antioxidant capacity (VCEAC) of phenolic phytochemicals. J Agric Food Chem. 2002;50(13):3713-7. doi: 10.1021/ jf020071c.

25. Sadraei H, Ghanadian M, Asghari G, Sekhavati N. Antispasmodic activity of apigenin and luteolin, two components of Dracocephalum kotschyi extract, on rat ileum contractions. J Herbmed Pharmacol. 2018;7(2):1005. doi: 10.15171/jhp.2018.17.

26. Parker KL, Schimmer BP. Pituitary hormones and their hypothalamic releasing hormones. In: Brunton LL, Lazo JS, Parker KL, eds. Goodman and Gilman's The Pharmacological Basis of Therapeutics. 11th ed. New York: McGraw-Hill; 2006. p. 1489-510.

27. Gnanamanickam GJ, Llewellyn-Smith IJ. Innervation of the rat uterus at estrus: a study in full-thickness, immunoperoxidase-stained whole-mount preparations. J Comp Neurol. 2011;519(4):621-43. doi: 10.1002/cne.22515.

28. Holda JR, Oberti C, Perez-Reyes E, Blatter LA. Characterization of an oxytocin-induced rise in [Ca2+] $\mathrm{i}$ in single human myometrium smooth muscle cells. Cell Calcium. 1996;20(1):43-51. doi: 10.1016/s01434160(96)90049-4.

29. Unno T, Matsuyama H, Sakamoto T, Uchiyama M, Izumi Y, Okamoto H, et al. M(2) and M(3) muscarinic receptormediated contractions in longitudinal smooth muscle of the ileum studied with receptor knockout mice. Br J Pharmacol. 2005;146(1):98-108. doi: 10.1038/sj.bjp.0706300.

30. Hollingsworth M. Mechanical responses of rat isolated uterine horns to transmural stimulation. Br J Pharmacol. 1975;55(1):41-6. doi: 10.1111/j.1476-5381.1975.tb07607.x.

31. Ratz PH, Berg KM, Urban NH, Miner AS. Regulation of smooth muscle calcium sensitivity: $\mathrm{KCl}$ as a calciumsensitizing stimulus. Am J Physiol Cell Physiol. 2005;288(4):C769-83. doi: 10.1152/ajpcell.00529.2004. 